\title{
UMA EDUCAÇÃO DO OLHO: AS IMAGENS NA SOCIEDADE URBANA, INDUSTRIAL E DE MERCADO
}

\author{
Carlos Eduardo Albuquerque Miranda*
}

\begin{abstract}
Sabe-se que a relação do olho com o cérebro é intima, estrutural. Sistema nervoso central e órgãos visuais externos estão ligados pelos nervos ópticos de tal sorte que a estrutura celular da retina nada mais é que a expansão da estrutura celular do cérebro. O anatomista norte americano Stephen Poliak chegou a admitir a hipótese revolucionária de que o tecido cerebral resultou de uma evolução dos olhos em pequenos organismos aquáticos que viveram a mais de um bilhão de anos atrás. Quer dizer: não foi o cérebro que se estendeu até a formação do órgão visual, mas, ao contrário, foi o olho que se complicou extraordinariamente dando origem ao córtex onde, supõe-se, estaria a sede da visualidade.
\end{abstract}

(Bosi, 1989)

\begin{abstract}
RESUMO: Neste artigo, pretendemos pensar o processo de produção industrial de imagens como parte de um programa de educação visual, cujas origens históricas antecedem o atual desenvolvimento industrial. Nossa hipótese é de que a valorização irrefletida da produção e do consumo de imagens através de aparelhos tecnológicos reproduz e intensifica a desvalorização dos sentidos na produção de conhecimento e re-valoriza o pensamento "cartesiano", educando o olho a ver o homem e o mundo conforme as possibilidades e os limites destas formas de representação da realidade. A ausência de uma atitude crítica em relação aos processos de produção destas imagens e o desconhecimento de suas origens históricas fazem com que a escola incorpore, de forma conservadora, o programa de educação visual acima referido e eduque, de forma alienada, o olho a ver a realidade.
\end{abstract}

Palavras-chave: Educação, Imagem, Olhar, Tecnologia, Descartes.

\footnotetext{
* Professor da Faculdade de Educação/Unicamp, coordenador associado do "Laboratório de Estudos Audiovisuais Olho", da Área Temática "Educação, Conhecimento, Linguagem e Arte" e presidente da Comissão de Trabalho "Educação e TV Unicamp”. E-mail: ceamira@terra.com.br
} 
Descartes (1973) considerava que a origem em quase todos os erros em filosofia estava não no fato de estarmos acostumados a considerar o suficiente as máquinas.

O corpo humano cartesiano, tomado pela expressão "corpo máquina" e criticado pela separação entre corpo e alma, ao longo de mais de três séculos, foi alvo dos mais variados tipos de crítica. Ao nosso ver, no entanto, o "olhar" cartesiano, este que pondera nossa displicência em relação às máquinas, permanece em nosso mundo contemporâneo, seja projetado em desejos e formas de ver o mundo, seja materializado em aparelhos de produção e reprodução da imagem.

Cumpre-nos, neste artigo, mostrar esta permanência, abordando apenas uma parte deste corpo cartesiano, o olho. Assim sendo, pretendemos abordar as imagens e sons em movimento e seu modo de produção industrial - cinema, TV, vídeo, Internet e outros -, inicialmente, pensando na distinção entre olho e olhar. Bosi ajuda-nos a pensar melhor esta distinção:

Se, em português, os dois termos aparentemente se casam, em outras línguas, a distinção se faz clara ajudando o pensamento a manter as diferenças. Em espanhol: ojo é o órgão; mas o ato de olhar é mirada. Em francês: oeil é o olho; mas o ato é regardlregarder. Em inglês: eye não está em look. Em italiano, uma coisa é o occhio e outra é o sguardo. Creio que essa marcada diversidade em tantas línguas não se deva creditar ao mero acaso: trata-se de uma percepção, inscrita no corpo dos idiomas, pela qual se distingue o órgão receptor externo, a que chamamos 'olho', e o movimento interno do ser que se põe em busca de informações e de significações, que é propriamente o 'olhar'. (Bosi, 1989)

A distinção inicial entre o olho e o olhar movimenta nosso pensamento na direção de uma outra distinção, entre Educação do Olho e Educação do Olhar.

Por Educação do Olhar podemos entender a educação do movimento interno do ser a que se refere Bosi. Neste sentido, a literatura educacional, preocupada com o acesso dos estudantes a diferentes produtos da indústria de imagens e sons em movimento, tem abordado, constantemente, a necessidade de compreendermos estes produtos e de pensarmos uma metodologia para trabalhar com ou a partir deles.

A expressão "Educação do Olhar" tornou-se, portanto, moeda corrente nos textos que pretendem abordar, em geral, as relações entre escola e cultura. Seus autores justificam o uso da expressão pela necessidade e função da escola em formar espectadores críticos. 
Quando propomos a expressão "Educação do Olho", queremos nos afastar desta preocupação pedagógica (o que não significa afastarmo-nos de uma reflexão da educação). Queremos pensar a produção industrial de imagens e sons em movimento como parte de um programa de educação visual, que é anterior ao desenvolvimento tecnológico da produção industrial de imagens e que vem, segundo Almeida (1999), produzindo as imagens da nossa memória e as formas da nossa imaginação do real.

Por Educação do Olho estamos tentando pensar origens históricas da produção industrial da cultura, considerando esta última como parte de um programa estético/político mais amplo do que o momento de sua configuração industrial. Tal programa antecede ao desenvolvimento tecnológico do século XIX, necessário para a consolidação da cultura industrial.

Tentemos perceber o que é próprio e específico do século XIX em relação ao olho e ao olhar. Dentre muitas mudanças em relação à percepção deste século, destacamos o olhar através dos aparelhos. Este olhar não é uma novidade do século em questão, no entanto, a possibilidade de produzir e reproduzir imagens a partir de aparelhos, inclusive de forma e em escala industrial, é uma das características específicas daquele século. Afinal, é o século da fotografia e do cinema e, podemos dizer, o da construção da indústria das imagens e sons em movimento.

A expressão "Educação do Olho", portanto, pretende chamar a atenção para as mudanças das formas de visibilidade do real que o olhar dos aparelhos provoca. Aprendemos (e, portanto, fomos educados) a pensar o olho como um órgão, como um aparelho. Tal percepção do olho legitima os aparelhos tecnológicos como extensão, aprimoramento, correção e ampliação do nosso sistema visual. Talvez, ao contrário do que fizemos inicialmente neste artigo, a forma como pensamos o olho (que, volto a dizer, nos é educada) não pode estar separada da forma como pensamos o olhar, pois a compreensão do corpo e de seus "movimentos" permite-nos compreender a alma e de seus movimentos, conforme nos ensinou Descartes.

Antes, porém, de considerar o "olhar" cartesiano e o seu corpo mecânico, vamos aprofundar um pouco mais nossa reflexão sobre o momento de construção da cultura industrial no século XIX. Lembrando sempre que estamos interessados no "olhar" através dos aparelhos.

Pultz e Mondenard afirmam que no século XIX consolidam-se novas formas de satisfazer uma antiga ambição de reconstrução da realidade. $\mathrm{O}$ retrato fotográfico, por exemplo, tornou-se possível graças ao tempo de exposição necessário para a produção de uma fotografia ter sido reduzido de vários minutos para quinze ou vinte e cinco segundos. Os estúdios, ini- 
cialmente freqüentados somente pela burguesia abastada, a partir de 1850 multiplicaram-se nas cidades e daguerreotipistas ambulantes popularizaram o novo procedimento nos campos. A maioria apresentava os corpos, simplesmente, sem acessórios, e produziam retratos rígidos com fundos uniformes, esvaziados de todo contexto social. Estas imagens não tinham, em síntese, outra ambição senão reproduzir a realidade. Apreciados por seu poder de tornar presente um ser ausente ou morto, os daguerreótipos, mesmo os mais rudimentares, asseguravam que o corpo representado era único (Pultz e Mondenard, 1995).

Xavier, abordando as reaçōes que a imagem cinematográfica despertou nos primeiros anos, destaca duas condiçóes particulares desse século para explicar estas reaçóes: a primeira era a valorização de um modo particular de figuração do real (ponto de vista - perspectiva renascentista) e a segunda, a instauração deste tipo de "olhar" como modelo de objetividade visual; é a proximidade deste modelo com o modo de "ver" da lente que constitui uma das bases para o efeito de realismo da fotografia. Xavier (1978) observa que:

Havia o desejo de reproduzir as condições naturais da percepção de um elemento qualquer, em termos de imagem e também de som. Neste sentido, o cinema e o fonógrafo constituíram duas cristalizações desta vontade. Se por algum tempo estiveram separados, a sua fusão no cinema falado coroou todo processo de desenvolvimento técnico promovido dentro da orientação rumo à duplicação do 'real' percebido. Nos fins do século XIX, se a captação e a reprodução de um determinado som já constituía a duplicação de um movimento, em termos de imagem era insuficiente à fidelidade à aparência de algo fixado num instante (fotografia).

A reprodução do real através dos aparelhos não é apenas o produto de uma possibilidade tecnológica. Ambição, como afirmam Pultz e Mondenard, ou desejo, como afirma Xavier, a reprodução do real remonta a uma concepção de imagem gestada e desenvolvida na Renascença. Isso nos faz pensar que abordar a produção industrial de imagens e sons em movimento apenas como uma indústria ou um mercado é um empobrecimento tanto do tema como da história. Por isso é que propomos pensar esta produção como parte de um projeto de educação visual mais amplo, que pode nos remeter à perspectiva Renascentista e ao "olhar" cartesiano.

Ainda pensando no "olhar" através dos aparelhos, lembramos o que nos diz Almeida quanto às produções de imagens e sons em movimento, sejam documentários e reportagens com a intenção de exibirem a realidade, sejam produções cinematográficas e televisivas, com intenção de exibirem ficção: 
[...] São recriações, a sua maneira, do real. O que é este 'a sua maneira': retiram do fluir contínuo do real em vida, pequenos pedaços - filmagens - e, após todo processo de produção, os reapresentam em seqüência temporal - projeção. Não mais o fluir contínuo do real em vida, mas o fluir contínuo do real em movimento. Suprimida a dispersão inerente ao real em vida, os seus pedaços filmados tornam-se indefesas seqüências submetidas à produção em estética e ideologia do real em movimento. (Almeida, 2001)

A expressão "recriações, a sua maneira, do real", em relação às produções em imagens e sons, põe em questão o que Xavier chama de um modo particular de figuração do real, valorizado no século XIX e que instaura de um tipo de "olhar" como modelo de objetividade visual. O olhar dos aparelhos, ou através deles (lembrando que o olho é considerado um aparelho), contribuirá para esta valorização e esta instauração, inclusive pela possibilidade de transformar o real vivido em real em movimento.

Xavier ainda nos fala da vontade de reproduzir as condições naturais da percepção de um elemento qualquer, em termos de imagens e sons. Quanto à discussão das percepçóes, remetemo-nos a Benjamin (1993) sobre a experiência do cinema:

Diante do filme, isso [a contemplação] não é possível. Mas o espectador percebe uma imagem, ela não é mais a mesma. Ela não pode ser fixada, nem como um quadro nem como algo de real. A associação de idéias do espectador é interrompida imediatamente, com a mudança de imagens. Nisso se baseia o efeito de choque provocado pelo cinema, que, como qualquer outro choque, precisa ser interceptado por uma percepção aguda. O cinema é a forma de arte correspondente aos perigos existenciais mais intensos com os quais se confronta o homem contemporâneo. Ele corresponde a metamorfoses profundas do aparelho perceptivo, como a que experimenta o passante, numa escala individual, quando enfrenta o tráfico, e como as experimenta, numa escala histórica, todo aquele que combate à ordem social vigente.

Benjamin claramente afirma que o cinema, a fotografia e todo aparato industrial de produção de imagens e sons, ao invés de reproduzirem as condições naturais da percepção, alteram-nas. Somos educados pelos sons e imagens produzidas pelos aparelhos. Nossa percepção está sendo educada na experiência do choque, educação que, por sua vez, é anterior ao cinema, pois já se faz presente nas grandes cidades do início do século XIX, como destacam os trabalhos literários de Edgar A. Poe e Baudelaire. Por isso, não 
podemos reduzir a compreensão do cinema ao seu caráter industrial; é necessário pensá-lo também como arte urbana (mesmo que os processos de urbanização e industrialização sejam vistos como imbricados e complementares, eles não são idênticos e mecanicamente articulados).

Os termos "a sua maneira", de Almeida, e "experiência do choque", de Benjamin, tencionam a idéia de um modelo de objetividade visual valorizada no século XIX. O primeiro, ao mesmo tempo, demonstra o porquê do efeito de realismo das imagens produzidas por aparelhos e revela a não objetividade destas imagens. O segundo aborda uma transformação da percepção que não se limita à experiência do cinema. Nossa percepção é educada pelo cinema (e, poderíamos dizer, pela TV e pelo vídeo), mas para sermos educados pelo cinema estamos, a muito, sendo educados pelas grandes cidades.

A preocupação com a verdade na representação do real não se resume às produçôes em imagens e sons em movimento. Zola, em seu livro Do romance, destaca a necessidade do romance moderno valorizar menos a imaginação em favor do real. Para ele, a descrição, por exemplo, tem a necessidade do emprego do método científico. O escritor do romance naturalista, para o romancista francês, deve agir como o crítico, ou seja, preocupar-se com o meio e com as circunstâncias da história que está sendo contada. Sobre a liberdade do escritor de inventar, Zola (1995) afirma:

[...] Pouco importa o trabalho que vai se seguir, desde que o método de construção empregado pelo romancista seja idêntico ao do crítico. $\mathrm{O}$ romancista parte da realidade do meio e da verdade do documento humano; se em seguida ele a desenvolve num certo sentido, já não é a imaginação, a exemplo dos contistas, é dedução, como entre os cientistas. Por sinal, não tive a pretensão de que os resultados fossem completamente semelhantes no estudo de um escritor e no estudo de uma personagem; aquele, com certeza, aproxima-se do real mais de perto, ainda que deixando um amplo espaço para a intuição. Todavia, digo-o ainda, o método é o mesmo.

Assim, podemos dizer que ciência, tecnologia, arte, indústria e cidade mesclam-se numa poderosa forma de educação do "olhar" através dos aparelhos. Vejamos agora como a Educação do Olho participa deste programa da educação do "olhar".

Relembremos que podemos tomar como uma das origens dispersa da histórica da objetividade visual a busca do "olhar correto" da perspectiva renascentista. Nosso interesse, neste momento, não é tanto o "olhar correto", mas a formulação de um "pensar correto", esta sim, uma busca que necessita 
educar não apenas o olhar, ou seja, a alma e seus movimentos, mas, também, o olho, ou seja, o corpo e seus movimentos. Segundo Almeida, a perspectiva tornou-se, a partir da Renascença, um aparato intelectual e técnico, pensado como ciência, objetivamente produzido para aprisionar o real, reproduzi-lo e afirmar-se como sua única e competente representação.

Para Almeida, a perspectiva renascentista, ao produzir-se como teoria e prática da representação do real, neutra, lógica e científica, produzirá ao mesmo tempo, em ilusão geométrica e matemática, a estética do poder burguês laico e religioso. Como ciência, produzirá os instrumentos para o enquadramento do real e tornará locais republicanos, burgueses, nobres, tirânicos em locais e imagens inesquecíveis de riqueza e pobreza, felicidade e tragédia. Como e com a ciência, constituirá a forma dominante de representação do real e ao longo do tempo, serva constante da Política, será $\mathrm{O}$ real (Almeida 1999).

Temos como objetivo demonstrar que há uma Educação do Olho que participa de uma Educação do Olhar e que, portanto, participa também de um programa de educação visual explícito acima. Vamos tomar como ponto de partida desta Educação do Olho o trabalho do filósofo francês René Descartes em relação às paixões da alma.

Descartes, em As paixões da alma, mais do que explicar as paixões e determinar uma relação causal entre corpo e alma em relação a elas, propõe, neste texto, uma educação das paixões, e, por conseguinte, uma educação da alma e do corpo.

Para abordar as paixões da alma, Descartes, inicialmente, irá distinguir o que é próprio da alma do que é próprio do corpo. Nesta distinção, ele nos dará uma formulação precisa da idéia de corpo-máquina. Trata-se do artigo em que Descartes distingue um corpo vivo de um corpo morto. Afirma ele no artigo 6:

(...) consideremos que a morte nunca sobrevem por culpa da alma, mas somente porque alguma das principais do corpo se corrompe; e julguemos que o corpo de um homem vivo difere do de um morto como um relógio, ou outro autômato (isto é, outra máquina que se move por si mesma), quando está montado e tem em si o princípio corporal dos movimentos para os quais foi instituído, com tudo o que se requer para a sua ação, difere do mesmo relógio, ou outra máquina, quando está quebrado e o princípio de seu movimento pára de agir. (Descartes, 1973) 
Vemos, assim, desenhar-se o corpo desalmado, pois não é a alma que anima o corpo. Corpos, relógios ou máquinas não devem à alma a causa de suas funçôes.

A necessidade de Descartes distinguir corpo e alma deve-se ao fato das paixôes, apesar de serem açóes da alma, terem como uma de suas origens as sensações do corpo. Portanto, para melhor conhecermos as paixões e para nos beneficiarmos delas é necessário saber como estas se criam e se instauram através dos movimentos do corpo.

O corpo desalmado de Descartes pode e deve ser governado pela alma. Para entendermos como isso pode se dar é preciso rever como Descartes pensa a relação entre corpo e alma.

A alma, apesar de estar unida ao corpo em todas as suas partes, não se relaciona com a extensão e com as propriedades da matéria. Suas funções são exercidas no corpo por meio de uma glândula do cérebro, muito sensível às modificações dos espíritos animais. Esta glândula, a pineal, é a principal sede da alma e, portanto, sede de suas paixóes. Além de sua mobilidade, justifica-se a pineal como sede da alma e das paixões, por um motivo muito particular em Descartes e que nos lembra a perspectiva renascentista e, por conseguinte, a máquina fotográfica e a máquina cinematográfica:

A razão que me persuade de que a alma não pode ter, em todo corpo, nenhum outro lugar, exceto essa glândula, onde exerce imediatamente suas funções, é que considero que as outras partes de nosso cérebro são todas duplas, assim como temos dois olhos, duas mãos, duas orelhas, e enfim todos os órgãos de nossos sentidos externos são duplos; e que, dado que não temos senão um único e simples pensamento de uma mesma coisa ao mesmo tempo, cumpre necessariamente que haja algum lugar aonde as duas imagens que nos vêm pelos dois olhos, onde as duas impressões que recebemos de um só objeto pelos duplos órgãos dos outros sentidos, se possam reunir em uma antes que cheguem à nossa alma, a fim de que não the representem dois objetos em vez de um só. E pode-se conceber facilmente que essas imagens ou outras impressões se reúnem nessa glândula, por intermédio dos espíritos que preenchem as cavidades do cérebro, mas não há qualquer outro local no corpo onde possam assim unir-se, senão depois de reunidas nessa glândula. (Descartes, 1973)

O movimento do pensamento cartesiano a respeito da unidade da alma leva-o a "escolher" a pineal como sede da alma e das paixões, reafirmando esta posição. O princípio de que temos um único e simples pensamento de uma mesma coisa, ao mesmo tempo, reforça a idéia de unicidade da alma e estabelece um princípio de distinção e clareza pelo qual o pensamento deve se conduzir diante da realidade confusa e caótica. A percepção 
dual, e por isso confusa, deve ser unificada, para ser clara e distinta. A dúvida racional, afastada de qualquer paixão ou emoção, ou sentimento, ou sensação, será o instrumento deste proceder.

O corpo-mecânico cartesiano, no entanto, apesar de todos os enganos a que está sujeito, devido à dualidade dos sentidos, fornece à alma uma possibilidade de distinção e clareza - a pineal. Se quisermos, podemos relacionar esta proposição cartesiana à busca do olhar correto da perspectiva renascentista.

Leonardo da Vinci, por exemplo, procurava, com os seus estudos da perspectiva, atribuir "ciência" à prática da pintura; advertia ele que a prática deve ser sempre edificada sobre a boa teoria e que a perspectiva é, desta, guia e entrada. Comenta Almeida a respeito deste projeto:

A Perspectiva, teoria desenvolvida a partir do ponto de vista de um olho só como ponto de convergência de linhas imaginárias do mundo sensível, devolve essas linhas em formas do real imaginado por ela mesma. Formas ideais do poder político e artístico para serem recordadas em reminiscência.

Aconselhada pela Prudência, que suspeita dos sentidos (...) a Perspectiva desabilita, assim, os dois olhos humanos que vêem o mundo verdadeiro, imperfeito, desarmônico, amoral, resistente ao poder, insuportável para ela e o poder que representa, alegoricamente. (Almeida, 1999)

Voltemos a Descartes. Poderíamos dizer que o mesmo movimento do pensamento da construção da perspectiva em Leonardo da Vinci está em Descartes, um século depois. Até mesmo a busca pela cientificidade os aproxima. Mas é mais do que isso. Descartes tenta demonstrar, no corpo, ou melhor, na natureza do corpo, o que Leonardo da Vinci escolhe como virtude em oposição aos viciosos olhos humanos. A perspectiva elaborada por da Vinci, eliminando a visão ambígua dos dois olhos, corresponde ao perfeito funcionamento da relação entre corpo e alma em Descartes. O ponto de fuga de da Vinci o leva à perfeição da representação da natureza. A pineal de Descartes corrige a duplicidade dos sentidos, a confusão das percepçôes e dos pensamentos. A máquina humana cartesiana naturaliza a perspectiva como a ciência do olhar correto. A idéia do "olho só", antes imaginada, um recurso técnico e artístico de Leonardo da Vinci, está agora no corpo cartesiano, faz parte da natureza humana, chama-se pineal.

Vejamos agora como Descartes descreve a forma como as impressões dos objetos se unem na glândula pineal. Afirma ele no artigo 35: 
Assim, por exemplo, se vemos algum animal vir em nossa direção, a luz refletida de seu corpo pinta duas imagens dele, uma em cada um de nossos olhos, e essas duas imagens formam duas outras, por intermédio dos nervos ópticos, na superfície interior do cérebro defronte às suas concavidades; daí, em seguida, por intermédio dos espíritos que enchem suas cavidades, essas imagens irradiam de tal sorte para a pequena glândula envolvida por esses espíritos, que o movimento componente de cada ponto de uma das imagens tende para o mesmo ponto da glândula para o qual tende o movimento que forma o ponto da outra imagem, a qual representa a mesma parte desse animal, por meio do quê as duas imagens existentes no cérebro compõem apenas uma única na glândula, que, agindo imediatamente contra a alma, lhe faz ver a figura desse animal. (Descartes, 1973)

Esta é uma das maneiras como as paixões se iniciam na alma. Quando a alma vê (e não os olhos), no caso, o animal, ela é excitada a agir, reagir ou sentir algo. Este algo é uma paixão da alma.

Podemos ver o movimento corporal interno de impressão da imagem de um objeto na alma como o movimento de impressão da imagem de um objeto numa película ou numa fita magnética. Por um lado, isso é mais claro no caso da película, onde podemos ver as reações da pineal e da alma como reações químicas provocadas pela luz; por outro, na fita magnética, por causa da idéia de que os espíritos animais provocam registros na glândula e no cérebro, lembrando a forma como as imagens são gravadas nessas fitas.

Nossa aproximação do funcionamento do olho cartesiano com a máquina cinematográfica ou fotográfica não é original. Aumont, em seu livro $A$ imagem, ao referir-se à visão como um sistema visual, afirma que o olho assemelha-se até certo ponto a uma máquina fotográfica; se a retina é comparável a uma espécie de chapa sensível, o essencial da percepção visual realiza-se depois, através de um processo de tratamento da informação que, como todos os processos cerebrais, está mais próximo dos modelos informáticos ou cibernéticos do que dos modelos mecânicos ou ópticos ("mais próximo" não querendo dizer que estes modelos sejam necessariamente adequados). (Aumont, 1993).

Vemos em Aumont a permanência do que podemos chamar de "olhar" cartesiano, o "olhar" mecânico que cria o corpo-máquina cartesiano. Percebemos isto pelo sentido da comparação do corpo com modelos, sejam eles mecânicos, ópticos, informáticos ou cibernéticos. Tal comparação, muitas vezes, considerada até mesmo didática, reforça talvez não a idéia do corpo mecânico cartesiano, mas sim do "olhar" cartesiano, ou seja, de um olhar que parte da separação entre corpo e alma em busca de um modelo de funcionamento próprio do corpo que independa da alma. $\mathrm{O}$ modelo pode 
não ser mecânico, pode ser cibernético, informático, ou qualquer outra coisa, o movimento é o mesmo. E não se trata de espiritualizar o corpo, pois não estamos discutindo a crença numa alma independente do corpo. Ao contrário, estamos tentando pensar corpo e alma como um só ser. Poderíamos substituir o termo alma por subjetividade ou psique. Mantivemos o termo por considerarmos que ele leva-nos a pensar o que, em nós, não se resume a um relógio.

Voltando à comparação entre o olho cartesiano e as máquinas, ou aparelhos de produção e reprodução de imagens, a rigor, a possibilidade de registro e análise de um "olhar" mecânico surgirá somente no século XIX, com a fotografia, que combina mecânica, óptica e química num único aparelho, na busca de reproduzir o olhar humano. Vemos, então, a fotografia dando significado à busca cartesiana de construção de um método de olhar o corpo humano e do próprio olhar do corpo humano.

Este "olhar", à medida que ganha legitimidade científica, por conseguir ver na natureza leis mecânicas, torna o corpo-máquina cartesiano natural, podendo até ser chamado de corpo cibernético ou corpo informático. É um "olhar" que deseja e produz a imagem de um corpo como "máquina” e que observamos como permanente nas descrições do sistema visual de Aumont. Recordemos que este "olhar" cartesiano tem como fundamento a forma como as paixões da alma são produzidas e mantidas através da pineal. Recordemos também que, por homologia, pudemos ver, na produção das paixões da alma na pineal, através de imagens, a produção das imagens fotográficas e cinematográficas. Assim sendo, mais do que observar uma concepção de corpo-máquina interessa-nos perceber um "olhar" que produz e projeta a mecanicidade, ou qualquer outro modelo, sobre as coisas em que pousa o seu olhar. Neste sentido é que podemos perceber uma história que se constitui num programa de educação visual, no qual o "olhar" cartesiano vai nos ensinando a ver o mundo como matemático.

Lisa Cartwright, ao estudar o cinema como uma instituição e um aparato para monitorar, regular e estruturar a "vida" na moderna cultura da ciência médica ocidental, apresenta uma série de exemplos históricos do uso do cinema na ciência médica para análise, regulação e configuração do que ela chama de transitório e incontrolável campo do corpo.

Para nós, interessa uma das proposiçôes de Lisa em relação ao olhar através dos aparelhos. Este olhar dá impulso à segmentação, mensuração e quantificação dos movimentos do corpo e dá visibilidade às suas partes internas. Lisa propõe que antes de ser um aumento dos sentidos do observador científico (como alguns estudiosos sugeriram e ainda sugerem), os aparelhos promovem uma substituição da percepção sensorial. Segundo 
ela, as observações produzidas pelos aparelhos técnicos em laboratórios de fisiologia substituem as observações sensoriais do médico e do técnico como uma privilegiada fonte de conhecimento científico. Ao invés de um acréscimo, trata-se de uma substituição (Cartwright, 1995).

Não queremos questionar aqui benefícios advindos do avanço tecnológico que permite o olhar através dos aparelhos. Questionamos que este olhar seja extensão, aprimoramento, correção e ampliação do nosso olho. Trata-se de um outro olhar que, como vimos, reconstrói, a sua maneira, o real; e que nos proporciona uma outra experiência perceptiva.

A modelagem do corpo e do olho em formulações de base matemática é um processo do qual faz parte o olhar através dos aparelhos. No entanto, como vimos, é anterior ao surgimento da possibilidade técno-industrial de produção de imagens e sons. Neste sentido é que vemos a permanência histórica do chamado "olhar" cartesiano e, poderíamos dizer, um impulso e um aprimoramento deste no século XIX. Além disso, quanto mais o corpo é considerado ou comparado a modelos matemáticos, menos as percepções e sensações são valorizadas na produção de conhecimentos. Descartes, ao menos, nos deixou a pineal.

Diante desta nossa hipótese é que nos perguntamos: o que os professores e demais profissionais da educação estão esperando da tecnologia, esteja ela materializada em vídeos, filmes, computadores ou redes? Talvez seja muito mais importante para a educação perceber como estas tecnologias, na forma como estão constituídas, nos educam, do que ficar pensando em como educar através delas. Não se trata de negar o seu uso na educação formal e informal, mas sim de lembrar sempre que as tecnologias de produção, reprodução de imagens, sons e palavras, em movimento ou não, constróem, a sua maneira, o real.

\section{AN EDUCATION OF THE EYE:}

THE IMAGES IN THE SOCIETY URBAN, INDUSTRIAL AND OF MARKET

ABSTRACT: In this article, we intend to think the process of industrial production of images as part of a program of visual education, whose historical origins precede the current industrial development. Our hypothesis is that the thoughtless valorization of the production and consumption of pictures through technological apparels reproduces and intensifies the depreciation of the senses in the knowledge production and revalues the "Cartesian" thought, educating the eye to see the man and the world agreement the possibilities and the limits of these ways of representation of the reality. The absence of a critical attitude in relation to the processes of 
production of these images and the ignorance of its historical origins do with that the school incorporates, in a conservative way, the program of visual education above referred and educate, in an alienated way, the eye to see the reality.

Key words: Education, Picture, Look, Technology and Descartes.

\section{Referências bibliográficas}

ALMEIDA, Milton José de. Cinema: Arte da memória. Campinas: Autores Associados, 1999. 150p.

. "A liturgia olímpica". In: Corpo e História (Coleção Educação

Contemporânea), Campinas: Autores Associados, 2001, p. 79-108.

AUMONT, Jacques. A Imagem. Trad. de Estela dos Santos Abreu. Campinas: Papirus, 1993. 317p.

BENJAMIN, W. "A obra de arte na era de sua reprodutibilidade técnica”.(1935-1936). In: Benjamin, Walter, Obras Escolhidas: Magia e técnica, arte e política. Vol. 1, Trad. de Sergio Paulo Rouanet. São Paulo: Brasiliense, 1993, p. 165-196.

BOSI, Alfredo. "Fenomenologia do olhar". In: NovaES, Adauto (org.) $O$ Olhar. São Paulo: Companhia das Letras, 1988, p. 65-87.

DESCARTES, R. "As Paixões da Alma" (1649). In: Descartes - Obras escolhidas. Trad. de J. Guinsburg e Bento Prado Junior. São Paulo: Difel, 1973, p. 295-404. (Col. Clássicos Garnier da Difel - ed. original francesa: Éditions Garnier Frères, Paris, s/d).

CARTWRIGHT, Lisa. Screening the body. Minneapolis/US: University of Minnesota Press, 1997. 199p.

PULTZ, John \& MONDENARD, Anne. Le Corps Photographié. Paris: Flammarion, 1995.

XAVIER, Ismail. Sétima arte: Um culto moderno. (Série Debates). São Paulo: Perspectiva/Secretaria da Cultura, Ciência e Tecnologia do Estado de São Paulo, 1978.

ZOLA, Émile. Do romance. Trad. de Plínio Augusto Coelho. São Paulo: Imaginário/USP, 1995. 231p. 